\title{
Clinical characteristics and mortality risk prediction in critically ill children in Malaysian Borneo
}

\author{
Indra Ganesan ${ }^{1,2}$, MD, MRCPCH, Terrence Thomas ${ }^{1,2}$, MD, MRCPCH, Fon En Ng², MBBS,
}

Thian Lian $\underline{S O O}^{2}$, MBBS, FRCP

\begin{abstract}
INTRODUCTION Mortality risk prediction scores are important for benchmarking quality of care in paediatric intensive care units (PICUs). We aimed to benchmark PICU outcomes at our hospital against the Pediatric Index of Mortality 2 (PIM2) mortality risk prediction score, and evaluate differences in diagnosis on admission and outcomes between Malaysian and immigrant children.

METHODS We prospectively collected demographic and clinical data on paediatric medical patients admitted to the PICU of Sabah Women's and Children's Hospital in Kota Kinabalu, Sabah, Malaysia. The PIM2 risk score for mortality was tabulated.

RESULTS Of the 131 patients who met the inclusion criteria, data was available for 115 patients. The mean age of the patients was $2.6 \pm 3.8$ years, with $79 \%$ of the cohort aged less than five years. Patients were mainly of Kadazan (38\%) and Bajau (30\%) descent, and $26 \%$ of patients were non-citizens. Leading diagnoses on admission were respiratory (37\%), neurological (18\%) and infectious (17\%) disorders. Out of the 29 patients who died, 23 (79\%) were Malaysians and the main mortality diagnostic categories were respiratory disorder (22\%), septicaemia (22\%), haemato-oncological disease (17\%) and neurological disorder (13\%). Calculated standardised mortality ratios (SMRs) were not significantly $>1$ for any patient category for variables such as age and admission diagnosis. However, infants less than two years old with comorbidities were significantly worse (SMR 2.61, 95\% confidence interval 1.02-6.66).

CONCLUSION The patient profile at our centre was similar to that reported from other PICUs in Asia. The PIM2 score is a useful mortality risk prediction model for our population.
\end{abstract}

Keywords: mortality risk prediction scores, paediatric intensive care

\section{INTRODUCTION}

Mortality risk prediction in the paediatric intensive care unit (PICU) is an important tool for auditing provision of care and evaluating outcomes. Although risk predictors of mortality identify risk factors present at the time of entry into intensive care, unique geographic, socioeconomic and genetic factors may potentially influence patient outcomes. Our PICU in Sabah, on the island of Borneo, Malaysia, caters to a large paediatric population of nearly one million children. The local population mainly consists of indigenous ethnic groups (53\%), among whom the Kadazan (18\%) and Bajau (14\%) people are predominant. There are also people of Chinese (10\%) and Malay (6\%) descent, as well as non-citizens, largely immigrants from the Southern Philippines and Indonesia, who make up 870,000 (28\%) of the 3.1 million population in Sabah. ${ }^{(1)}$ There may be innate differences influencing patient outcomes in Malaysian children compared to children of the immigrant population, whose parents are blue-collar workers from poorer socioeconomic backgrounds and are likely exposed to malnutrition and overcrowding.

Although many Malaysian PICUs use mortality risk prediction scores, no published study has yet documented how Malaysian PICU outcomes benchmark against these scores. The primary aim of our study was to benchmark our hospital's PICU outcomes against the Pediatric Index of Mortality 2 (PIM2) ${ }^{(2)}$ mortality risk prediction score. The secondary aim was to evaluate differences in diagnoses on admission and outcomes between Malaysian and non-Malaysian children.

The PIM2 score $^{(2)}$ was preferred, as it is more readily available for use compared to the proprietary Pediatric Risk of Mortality III (PRISM III) score. ${ }^{(3)}$ A recent comparative study from Hong Kong showed similar risk prediction of mortality using these two models, thus validating the usefulness of both scores in an East Asian population. ${ }^{(4)}$

\section{METHODS}

All consecutive critically ill patients (aged 30 days to 15 years) admitted to the PICU at Sabah Women and Children's Hospital (SWACH), Kota Kinabalu, Sabah, Malaysia, from April to December 2010 were included in the study. Critically ill patients were defined as those needing inotropic support (for cardiovascular failure) or assisted ventilation (for respiratory failure). Patients transferred to the PICU for continued care from the neonatal intensive care unit (NICU) and medical patients admitted for high dependency care without cardiovascular or respiratory failure were excluded. Paediatric surgical patients were admitted to an independent surgical intensive care

${ }^{1}$ Department of Paediatrics, KK Women's and Children's Hospital, Singapore, ${ }^{2}$ Paediatric Department, Sabah Women's and Children's Hospital, Kota Kinabalu, Sabah, Malaysia

Correspondence: Dr Indra Ganesan, Consultant, Nephrology Service, KK Women's and Children's Hospital, 100 Bukit Timah Road, Singapore 229899. Indra.Ganesan@kkh.com.sg 
Table I. Pediatric Index of Mortality 2 score parameters. ${ }^{(2)}$

\begin{tabular}{lc}
\hline A. Score $\mathbf{1}$ if “yes" for the following, $\mathbf{0}$ if “no" or "unknown”: \\
\hline Item & Beta \\
- Elective admission & -0.9282 \\
- Recovery post procedure & -1.0244 \\
- Cardiac bypass & 0.7507 \\
- High-risk diagnosis* & 1.6829 \\
- Low-risk diagnosis & -1.5770 \\
- No response of pupils to bright light & 3.0791 \\
- Mechanical ventilation & 1.3352 \\
B. Determine the following values: & \\
- SBP (mmHg; unknown = 120) & 0.01395 \\
- Base excess (value, unknown = 0) & 0.1040 \\
- FiO ${ }_{2}^{*} 100 / P a O_{2}$ (value, unknown = 0) & 0.2888
\end{tabular}

\section{Formula for calculating risk of mortality:}

1. Predicted death rate $=\mathrm{e}^{\text {Logit }} /\left(1+\mathrm{e}^{\text {Logit }}\right)$

2. Logit $=(-4.8841)+($ values * Beta $)+(0.01395 *$ absolute $\{\mathrm{SBP}-120\}])+(0.1040$ * [absolute base excess $])+$ $\left(0.2888\right.$ * $\left.\left[100 * \mathrm{FiO}_{2} / \mathrm{PaO}_{2}\right]\right)$

*High-risk diagnosis: cardiac arrest preceding ICU admission, severe combined immune deficiency, leukaemia or lymphoma after first induction, spontaneous cerebral haemorrhage, cardiomyopathy or myocarditis, hypoplastic left heart syndrome, HIV infection, liver failure is the main reason for ICU admission, neurodegenerative disorder.

${ }^{\dagger}$ Low-risk diagnosis (admission diagnosis): acute asthma, bronchiolitis, croup, obstructive sleep apnoea, diabetic ketoacidosis

$\mathrm{FiO}_{2}$ : fraction of inspired oxygen; HIV: human immunodeficiency virus; $I C U^{2}$ : intensive care unit; $\mathrm{PaO}_{2}$ : partial pressure of oxygen in arterial blood; SBP: systolic blood pressure

unit at our hospital. Approval for the study was obtained from the Malaysian Ethics and Medical Research Board, Ministry of Health, Malaysia.

Prospective data was collected on demographics, length of stay, ventilation days, diagnosis on admission and cause of death. Diagnosis on admission to the PICU was categorised according to the affected organ systems. Accordingly, meningitis was categorised as a neurological disorder, leukaemia with neutropenic sepsis was placed under haemato-oncology, and pneumonia as a respiratory disorder. Infectious diseases referred to laboratory-confirmed communicable diseases such as dengue, tuberculosis and malaria. Septicaemia was defined as having either a positive growth on peripheral blood cultures or clinical features of hypotension and multiorgan dysfunction. PIM2 risk items were tabulated and mortality risk prediction scores were calculated (Table I). ${ }^{(2)}$

Standard descriptive statistics were used for continuous variables, while categorical variables were reported as proportions (\%). Variables between Malaysian and immigrant children were compared using Student's t-test (normality assumed) or Mann-Whitney $U$ test (normality not assumed) for continuous data. The Kruskal-Wallis test was used to compare differences in diagnosis on admission between our study and previous reports from other PICUs. Receiver operating characteristic (ROC) analysis was used to evaluate the accuracy of mortality risk prediction using the PIM2 score, and standardised mortality ratios (SMRs) were determined in order to benchmark patient outcomes against the predicted PIM2 outcome. A p-value of $<0.05$ was considered to be statistically significant.
Table II. Patient characteristics.

\begin{tabular}{|c|c|}
\hline Characteristic & No. (\%) \\
\hline $\begin{array}{l}\text { Age }^{*} \text { (yrs) } \\
<2(n=78) \\
2-5(n=13) \\
>5(n=24)\end{array}$ & $\begin{array}{c}2.6 \pm 3.8(0.1-14.1) \\
0.5 \pm 0.4(0.1-1.8) \\
3.0 \pm 0.71(2.0-4.1) \\
9.3 \pm 2.5(5.4-14.1)\end{array}$ \\
\hline Weight* (kg) & $10.35 \pm 9.2(1.8-42.5)$ \\
\hline Height* $(\mathrm{cm})$ & $77.7 \pm 32.0(36-155)$ \\
\hline Male-to-female ratio & $1.0: 1.7$ \\
\hline $\begin{array}{l}\text { Ethnicity } \\
\text { Kadazan } \\
\text { Bajau } \\
\text { Chinese } \\
\text { Brunei } \\
\text { Malay } \\
\text { Non-Malaysian }\end{array}$ & $\begin{aligned} 44 & (38.2) \\
34 & (29.5) \\
4 & (3.4) \\
1 & (0.9) \\
2 & (1.7) \\
30 & (26.1)\end{aligned}$ \\
\hline $\begin{array}{l}\text { Comorbidities } \\
\text { Congenital heart disease } \\
\text { NICU graduates with } \\
\text { chronic lung disease } \\
\text { Malignancy } \\
\text { Chronic haemolytic anaemia } \\
\text { Genetic syndrome } \\
\text { Quadriplegia } \\
\text { Inborn error of metabolism } \\
\text { Bronchial asthma } \\
\text { Chronic infection } \\
\text { Miscellaneous }\end{array}$ & $\begin{array}{l}40(34.7) \\
9(7.8) \\
6(5.2) \\
5(4.3) \\
3(2.6) \\
3(2.6) \\
2(1.7) \\
2(1.7) \\
2(1.7) \\
2(1.7) \\
6(5.2)\end{array}$ \\
\hline No comorbidities & $75(65.2)$ \\
\hline Length of stay in PICU* (days) & $8.2 \pm 11.8(1-75)$ \\
\hline Assisted mechanical ventilation & $103(89.5)$ \\
\hline $\begin{array}{l}\text { Duration of mechanical } \\
\text { ventilation* (days) }\end{array}$ & $5.7 \pm 7.0(1-53)$ \\
\hline
\end{tabular}

*Data is presented as mean \pm standard deviation (range).

† Included children with haemophagocytic lymphohistiocytosis, autoimmune disorder, chronic liver disease, chronic rheumatic heart disease, skeletal disorder and severe failure to thrive.

NICU: neonatal intensive care unit; PICU: paediatric intensive care unit

\section{RESULTS}

Among the 269 patients admitted to the PICU during the study period, 131 were critically ill and satisfied the inclusion criteria. A total of 16 patients with incomplete data for PIM2 analysis were excluded, leaving a cohort of 115 patients in the final analysis. Table II presents the demographic characteristics and comorbidities of the patients. The mean age of the patients was $2.6 \pm 3.8$ (range 0.1-14.1) years, with a male-to-female ratio of 1.0 to 1.7 . In all, 91 (79.1\%) children were aged $<5$ years. The biggest ethnic groups were Kadazan ( $n=44,38.2 \%$ ) and Bajau ( $\mathrm{n}=34,29.5 \%)$, while 30 (26.1\%) children were noncitizens. Comorbidities were observed in 40 (34.7\%) children, the most common being congenital heart disease $(n=9,7.8 \%)$, NICU graduates with chronic lung disease $(n=6,5.2 \%)$ and malignancy ( $\mathrm{n}=5,4.3 \%$ ). The average length of stay in the PICU was $8.2 \pm 11.8$ (range 1-75) days. Most children $(\mathrm{n}=103,89.5 \%$ ) received assisted mechanical ventilation over a mean duration of $5.7 \pm 7.0$ (range 1-53) days.

Admission diagnosis was significantly different between Malaysian and non-Malaysian children ( $p=0.01$; Table III). Respiratory disorders (27.1\%), neurological disorders (primarily neurological infections; $22.3 \%$ ) and infectious diseases (16.5\%) 
Table III. Comparison of Malaysian and non-Malaysian children.

\begin{tabular}{|c|c|c|c|}
\hline \multirow[t]{2}{*}{ Variable } & \multicolumn{2}{|c|}{ No. (\%) } & \multirow[t]{2}{*}{ p-value } \\
\hline & $\begin{array}{l}\text { Malaysian } \\
(\mathrm{n}=85)\end{array}$ & $\begin{array}{l}\text { Non-Malaysian } \\
\quad(n=30)\end{array}$ & \\
\hline Age* (yrs) $^{*}$ & $2.7 \pm 4.0(0.1-14.1)$ & $2.3 \pm 3.0(0.1-10.7)$ & 0.56 \\
\hline Male-to-female ratio & $1.0: 0.5$ & $1.0: 0.60$ & 0.67 \\
\hline Comorbidity & $37(43.5)$ & $3(10.0)$ & $0.002^{+}$ \\
\hline $\begin{array}{l}\text { Diagnosis on admission, by organ system } \\
\text { Anaphylaxis } \\
\text { Cardiovascular disease } \\
\text { Neurological disorder } \\
\text { Gastroenterological disorder } \\
\text { Haemato-oncological disease } \\
\text { Infectious disease } \\
\text { Metabolic disease } \\
\text { Renal disease } \\
\text { Respiratory disorder } \\
\text { Septicaemia }\end{array}$ & $\begin{aligned} 0 & (0) \\
10 & (11.7) \\
19 & (22.3) \\
2 & (2.4) \\
6 & (7.1) \\
14 & (16.5) \\
1 & (1.2) \\
2 & (2.4) \\
23 & (27.1) \\
8 & (9.4)\end{aligned}$ & $\begin{array}{c}1(3.3) \\
1(3.3) \\
2(6.7) \\
1(3.3) \\
0(0) \\
5(16.7) \\
0(0) \\
0(0) \\
19(63.3) \\
1(3.3)\end{array}$ & $0.01^{+}$ \\
\hline Survival & $62(72.9)$ & $24(80.0)$ & 0.89 \\
\hline $\begin{array}{l}\text { Cause of death, by organ system } \\
\text { Cardiovascular disease } \\
\text { Neurological disorder } \\
\text { Haemato-oncological disease } \\
\text { Infectious disease } \\
\text { Metabolic disease } \\
\text { Respiratory disorder } \\
\text { Septicaemia }\end{array}$ & $\begin{aligned} 23 & (27.1) \\
3 & (13.0) \\
3 & (13.0) \\
4 & (17.4) \\
2 & (8.7) \\
1 & (4.3) \\
5 & (21.7) \\
5 & (21.7)\end{aligned}$ & $\begin{array}{l}6(20.0) \\
1(16.7) \\
1(16.7) \\
3(50.0) \\
1(16.7)\end{array}$ & 0.26 \\
\hline
\end{tabular}

${ }^{*}$ Data is presented as mean \pm standard deviation (range). ${ }^{\dagger} p<0.05$ was considered statistically significant.

were common among Malaysian children. Nearly two-thirds of the non-citizens had respiratory disorders (63.3\%). Chronic comorbidities were mainly seen among Malaysian children $(p=0.002)$. A similar spectrum was reflected in the cause of death. Mortality was highest among patients with respiratory disorders for both Malaysian (21.7\%) and non-Malaysian (50.0\%) children (Table III). Other important causes of death (based on the organ systems affected) among Malaysian children were septicaemia (21.7\%), haematological malignancy $(17.4 \%)$, neurological infections (13.0\%), and cardiovascular conditions such as congenital heart disease, myocarditis and chronic rheumatic heart disease (13.0\%).

SMRs were calculated for PIM2 risk scores with respect to age group and diagnosis on admission (Table IV). Children aged $<2$ years (SMR 1.68) and those aged $>5$ years (SMR 1.62) had worse outcome than expected. However, subgroup analysis showed that children in both age groups fared poorer when they had pre-existing comorbidities $(<2$ years: SMR 2.61 vs. 1.04 [no comorbidities]; > 5 years: 2.31 vs. 0.74 [no comorbidities]). The common comorbidities in the two age groups differed - chronic lung disease in NICU graduates and congenital heart disease were seen in the younger age group, whereas malignancy, chronic haemolytic anaemia, chronic rheumatic heart disease and autoimmune disease were seen among children aged $>5$ years. Children with haemato-oncological diseases, respiratory disorders, and septicaemia fared the poorest (SMRs 2.33, 1.63 and 1.74, respectively). Patients with all other diagnoses showed relatively balanced SMRs.

\section{DISCUSSION}

PIM2 and PRISM III are validated mortality risk prediction models widely used in developed and developing nations. . $^{(2,4-8)}$ Our study benchmarked well against the PIM2 score, with the SMRs in all patient groups not significantly different from 1.00. These risk prediction models were also used in two East Asian studies, thereby validating its use in this patient population. A study from Hong Kong by Choi et al compared PIM and PRISM III, with both models documenting acceptable SMRs of 0.61 (95\% Cl 0.50-0.77) and 0.79 (95\% Cl 0.65-0.98), respectively. ${ }^{(4)}$ Similarly, Goh et al from Malaysia, who compared the outcomes of children in community hospital transfers and internal transfers, reported an overall SMR of $0.88(95 \% \mathrm{Cl}$ 0.63-1.19) using PRISM II. ${ }^{(9)}$

Table $\mathrm{V}$ compares various studies on patient admissions to PICUs in developed and developing countries based on the diagnoses (excluding neonates, and trauma and postoperative patients ${ }^{(2,4,5,7,9-12)}$ Children with cardiac disorders, which include cardiac surgical and transplant patients, form the largest group by admission diagnosis in paediatric ICUs in high-income nations ${ }^{(13)}$ - the United Kingdom, Australia and New Zealand $(36 \%-51 \%)^{(2,5)}$ Admission diagnosis in our study population is comparable to those of other middle-income nations ${ }^{(14)}$ such as South Africa, India, Spain and Argentina, where respiratory (32\%-52\%), central nervous system (CNS) and cardiac disorders, and septicaemia predominate $(p=0.87) .^{(4,6,7,10)}$

Our hospital caters to a mainly rural and resource-limited population in North Borneo, Malaysia. ${ }^{(14)}$ The study by Goh et $\mathrm{al}^{(9)}$ from University Malaya Medical Centre, Kuala Lumpur, 
Table IV. Standardised mortality ratios based on PIM2 risk assessment with respect to diagnosis on admission and age of patients.

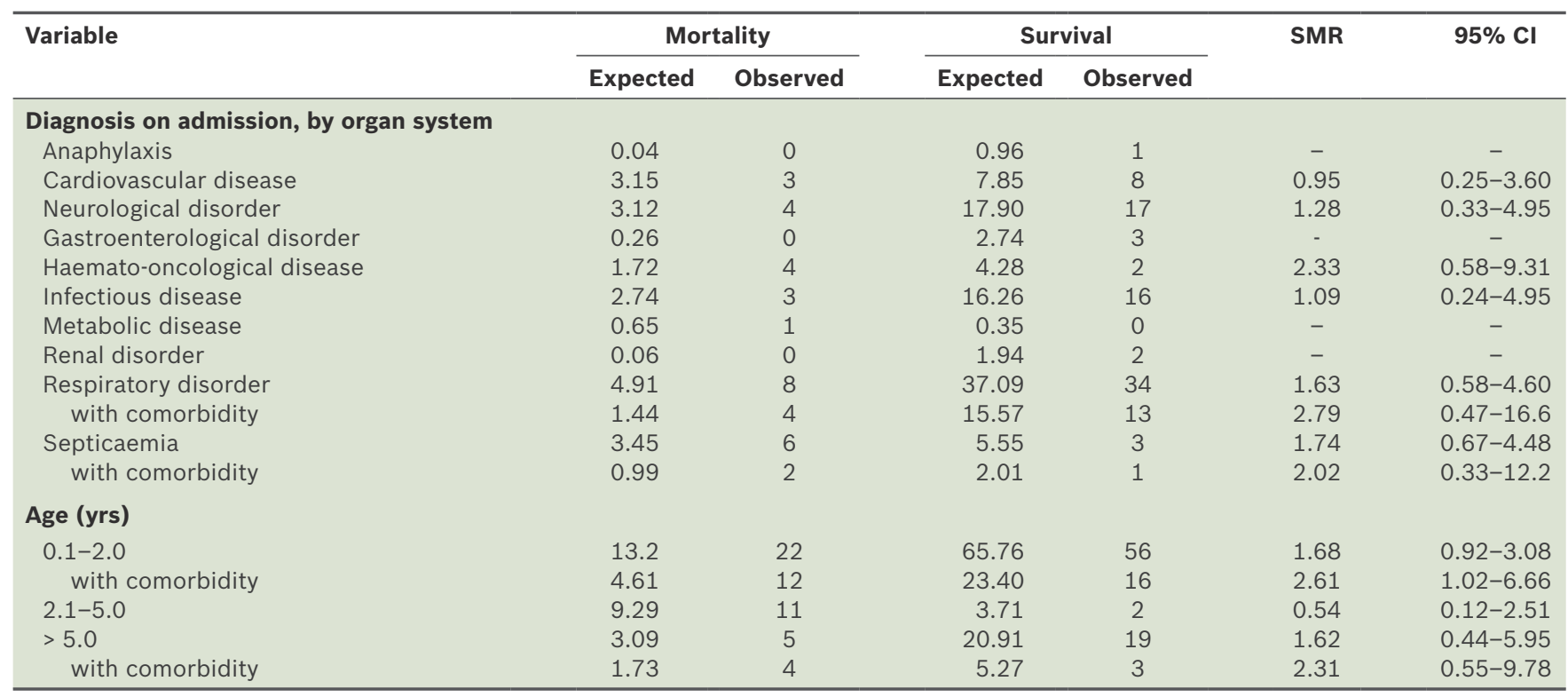

Cl: confidence interval; PIM2: Pediatric Index of Mortality 2; SMR: standardised mortality ratio

Table V. Paediatric ICU admissions by diagnosis, country and year(s) of study.

\begin{tabular}{|c|c|c|c|c|c|c|c|c|c|}
\hline & $\begin{array}{l}\text { Pearson } \\
\text { et } \mathrm{al}^{(5)}\end{array}$ & $\begin{array}{l}\text { Slater } \\
\text { et } \mathrm{al}^{(2)}\end{array}$ & $\begin{array}{l}\text { Wells } \\
\text { et } \mathbf{a l}^{(10)}\end{array}$ & $\begin{array}{l}\text { Tan } \\
\text { et } \mathbf{a l}^{(11)}\end{array}$ & $\begin{array}{l}\text { Goh } \\
\text { et } \mathbf{a l}^{(9)}\end{array}$ & $\begin{array}{l}\text { Choi } \\
\text { et } \mathrm{al}^{(4)}\end{array}$ & $\begin{array}{l}\text { Prieto } \\
\text { Espuñes } \\
\text { et } \text { al }^{(12)}\end{array}$ & $\begin{array}{l}\text { Canonero } \\
\text { et } \mathrm{al}^{(7)}\end{array}$ & $\begin{array}{l}\text { Present } \\
\text { study }\end{array}$ \\
\hline Total no. of patients* & $5,981^{+}$ & $14,864^{t, \neq}$ & 1,423 & 205 & 346 & 243 & 133 & 252 & 115 \\
\hline \multicolumn{10}{|l|}{ Diagnostic category ${ }^{\S}(\%)$} \\
\hline Cardiovascular disease & $51^{\| \prime}$ & $36 \|$ & - & 18 & 7 & 6 & 12 & 10 & 10 \\
\hline Neurological disorder & 13 & 13 & 9 & 20 & 12 & 23 & 14 & 16 & 18 \\
\hline $\begin{array}{l}\text { Gastroenterological } \\
\text { disorder }\end{array}$ & 1.9 & - & 5 & 7 & - & 3 & 3 & - & 3 \\
\hline $\begin{array}{l}\text { Haemato-oncological } \\
\text { disorder }\end{array}$ & 1.7 & -- & - & 3 & - & 2 & 3 & - & 6 \\
\hline Metabolic disorder & 0.5 & -- & - & 4 & - & 3 & 9 & - & 1 \\
\hline Renal disorder & 0.6 & -- & - & 4 & - & 2 & 5 & - & 1 \\
\hline Respiratory disorder & 15 & 30 & $48^{\|}$ & $30^{\prime \prime}$ & $52^{\|}$ & $49 \|$ & $32 \|$ & $41^{\|}$ & $37 \|$ \\
\hline Septicaemia" & 3.4 & - & 12 & 4 & 16 & 3 & - & 8 & 8 \\
\hline Miscellaneous & - & 21 & 27 & 10 & 12 & 15 & 11 & 25 & 1 \\
\hline
\end{tabular}

*Excludes neonatal, trauma, postoperative patients. ${ }^{\dagger}$ Includes cardiac surgical patients. ${ }^{\ddagger}$ Patient population included $13 \%$ neonates. ${ }^{\S}$ Diagnostic category as stated in the original papers, though not all papers carried the same list of diagnoses. "Most common diagnostic category in the study. "Septicaemia was not explicitly defined in all studies. UK: United Kingdom

Malaysia, in 1999-2000 yields the opportunity to compare and contrast differences in tertiary PICUs serving an urban and a rural Malaysian population. Although the overall range of diagnostic conditions between the two studies were similar ( $p=0.31$ ), patients from rural Malaysia (present study) showed apropensity toward neurological disorders, particularly neurological infections (18\% vs. $12 \%$ ), and infectious disorders (17\% vs. $0 \%$ ) compared to Goh et al's study. ${ }^{(9)}$

The high incidence of neurological infections in our study is remarkable given that the cohort of patients in the 1999 study by Goh et al ${ }^{(9)}$ were not immunised against Haemophilus influenzae type b (Hib), previously a leading cause of bacterial meningitis in Malaysia. ${ }^{(15)}$ The national average for Hib immunisation coverage in Malaysia in 2009-2010 was 95\%, thus conferring herd immunity in our cohort of children. ${ }^{(16)}$ Rates of bacterial meningitis in children have been shown to reduce dramatically in countries with a comprehensive Hib vaccination programme. ${ }^{(17)}$ However, incidence data on childhood CNS infections in Malaysia after Hib vaccination is not available. The leading infectious aetiologies identified in our patients with CNS infections were Streptococcus pneumoniae and Japanese encephalitis virus. A 1997 study $^{(11)}$ from urban Singapore, a neighbouring country, reported a similar spectrum of diagnoses among 205 medical patients, with the most common being respiratory (30\%) and neurological (20\%) disorders (Table V).

Non-Malaysian patients accounted for $26 \%$ of all admissions to our PICU. Although non-Malaysian children were more likely to have respiratory disorders $(p=0.01)$ and lack comorbidities 
$(p=0.002)$, there were no apparent differences with respect to mortality rates by diagnosis $(p=0.89)$.

The objectives of the United Nations Millennium Development Goals (MDG 4: Reduce Child Mortality) have brought into focus mortality in children under the age of five years. ${ }^{(18)}$ In our study, the SMR for PIM2 scores were acceptable for the age range of 2-5 years, but elevated in infants $<2$ years old with comorbidities. The comorbidities noted in our cohort are common to most tertiary Malaysian PICUs - infants with congenital heart disease or neonatal ICU graduates with chronic lung disease, and older children with malignancies, chronic haemolytic anaemia (mainly beta thalassaemia major) and chronic rheumatic heart disease (personal communication).

A limited number of comorbidities are 'high-risk diagnoses' on PIM2 scoring, including cardiac arrest preceding ICU admission, severe combined immune deficiency, leukaemia or lymphoma after first induction, spontaneous cerebral haemorrhage, cardiomyopathy, myocarditis, hypoplastic left heart syndrome, human immunodeficiency virus infection, liver failure and neurodegenerative disorders. ${ }^{(2)}$ Respiratory disorders (asthma, bronchiolitis and croup) are 'low-risk diagnoses' and serve to reduce the mortality risk prediction in the algorithm formula. (2) In our cohort, 10 children among the 16 with unexpected mortality (defined as death in children with an admission risk score $<25 \%$ ) had comorbidities. We found that exclusion of children with comorbidities improves the sensitivity of the PIM2 risk prediction model, giving a robust area under the curve of $77.5 \%$ upon ROC analysis when compared to $73 \%$ if all patients were included.

Mortality risk prediction scores such as PIM2 and PRISM serve as a constant audit of service provision and are useful for tracking improvements in healthcare delivery. ${ }^{(19)}$ This data also contributes to management decisions pertaining to the distribution of national healthcare resources and manpower planning. Our study confirms that the PIM2 mortality risk score is a useful indicator of the quality of PICU care in Malaysian hospitals. The PICU at Sabah Women's and Children's Hospital serving a rural population manages more children with neurological and respiratory disorders than hospitals in urban Malaysia. Infants with comorbidities were found to tend to have worse outcomes than those without comorbidities.

\section{REFERENCES}

1. Department of Statistics Malaysia. Population Distribution and Basic Demographic Characteristic Report 2010. Kuala Lumpur: Department of Statistics Malaysia; 2011.

2. Slater A, Shann F, Pearson G; Paediatric Index of Mortality (PIM) Study Group. PIM2: a revised version of the Paediatric Index of Mortality. Intensive Care Med 2003; 29:278-85.

3. Pollack MM, Patel KM, Ruttimann UE. PRISM III: an updated Pediatric Risk of Mortality score. Crit Care Med 1996; 24:743-52.

4. Choi KM, Ng DK, Wong SF, et al. Assessment of the Pediatric Index of Mortality (PIM) and the Pediatric Risk of Mortality (PRISM) III score for prediction of mortality in a paediatric intensive care unit in Hong Kong. Hong Kong Med J 2005; 11:97-103.

5. Pearson GA, Stickley J, Shann F. Calibration of the paediatric index of mortality in UK paediatric intensive care units. Arch Dis Child 2001; 84:125-8.

6. Singhal D, Kumar N, Puliyel JM, Singh SK, Srinivas V. Prediction of mortality by application of PRISM score in intensive care unit. Indian Pediatr 2001; 38:714-9.

7. Canonero I, Figueroa A, Cacciamano A, Olivier E, Cuestas E. [Validation of PRISM and PIM2 scores of mortality in a pediatric intensive care unit in Cordoba]. Arch Argent Pediatr 2010; 108:427-33. Spanish.

8. Gemke RJ, van Vught J. Scoring systems in pediatric intensive care: PRISM III versus PIM. Intensive Care Med 2002; 28:204-7.

9. Goh AY, Abdel-Latif Mel-A, Lum LC, Abu-Bakar MN. Outcome of children with different accessibility to tertiary pediatric intensive care in a developing country: a prospective cohort study. Intensive Care Med 2003; 29:97-102.

10. Wells M, Riera-Fanego JF, Luyt DK, Dance M, Lipman J. Poor discriminatory performance of the Pediatric Risk of Mortality (PRISM) score in a South African intensive care unit. Crit Care Med 1996; 24:1507-13.

11. Tan GH, Tan TH, Goh DY, Yap HK. Risk factors for predicting mortality in a paediatric intensive care unit. Ann Acad Med Singapore 1998; 27:813-8.

12. Prieto Espuñes S, López-Herce Cid J, Rey Galán C, et al. [Prognostic indexes of mortality in pediatric intensive care units]. An Pediatr 2007; 66:345-50. Spanish.

13. The World Bank. World Bank Atlas Method. Washington: The World Bank; 2011 [online]. Available at: http://data.worldbank.org/about/countryclassifications/world-bank-atlas-method. Accessed 1 September 2011.

14. Department of Statistics Malaysia. Report on Household Income Expenditure Survey, Malaysia 2009/10. Kuala Lumpur: Department of Statistics Malaysia; 2011.

15. Hussain IH, Sofiah A, Ong LC, et al. Haemophilus influenzae meningitis in Malaysia. Pediatr Infect Dis J 1998; 17(9 Suppl):S189-90.

16. Malaysia: WHO and UNICEF estimates of national immunization coverage: 2010 revision. Available at: http://www.childinfo.org/files Malaysia_1997_2010.pdf. Accessed 1 September 2011.

17. Thigpen MC, Whitney CG, Messonnier NE, et al. Bacterial meningitis in the United States, 1998-2007. N Engl J Med 2011; 364:2016-25.

18. Wong SL, Muhammad Ismail HI, eds. Study On Under Five Deaths in Malaysia 1993-2003: Where and Why 5000 Children in Malaysia are dying every year? Kuala Lumpur: Ministry of Health Malaysia; 2008.

19. Marcin JP, Pollack MM. Review of the acuity scoring systems for the pediatric intensive care unit and their use in quality improvement. J Intensive Care Med 2007; 22:131-40. 